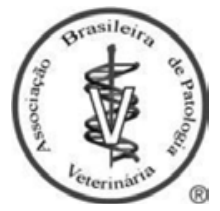

Diagnostic Exercise

From The Latin Comparative Pathology Group*

\title{
Granular Cell Tumor in the Brain of a Dog
}

\author{
Contributors:
}

Marisa Maglaty*1, Kevin D. Woolard ${ }^{1}$.

${ }^{1}$ Comparative Pathology Laboratory \& California National Primate Research Center. University of California, Davis.

*Corresponding author: E-mail: mamaglaty@ucdavis.edu

\section{Clinical History:}

10 year-old, female spayed, Golden Retriever/Poodle mix. This patient had a mass removed laparoscopically from the right adrenal gland (cortical adenoma) and was started on a low dose of prednisone post-operatively. Eight days postop, she began having cluster seizures and was started on levetiracetam therapy. The following day, the dog was moderately obtunded and stumbling. On neurological examination, mild generalized ataxia was noted along with decreased menace OS, and delayed proprioception in the left pelvic and left thoracic limbs. CBC and chemistry values were unremarkable except for a mild hepatic enzyme elevation. EEG showed seizure-like activity and abnormal brain waves resembling sleep state while awake. MRI revealed an eccentric right-sided mass extending over the frontal and parietal lobes with subtentorial herniation. Due to poor prognosis, euthanasia was elected.

\section{Necropsy Findings:}

Tenuously adhered to the right parietal lobe of the brain and the dura mater is a soft, round, white, plaque-like mass measuring $3.5 \times 3.0 \times 0.3 \mathrm{~cm}$. The mass is friable and poorly-demarcated from surrounding brain parenchyma. A portion of the mass adheres to the supradjacent surface of the calvarium (Fig.1-2).

\section{Follow-up questions:}

- Provide differential diagnoses for the gross and imaging results alone;

- Give a cytologic description of the impression smear/cytology;

- Describe the ultrastructural characteristics;

- Refine, and state your top differential given the cytological and ultrastructural character.

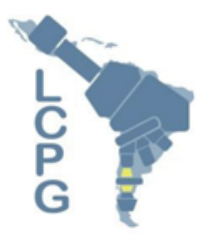

*The Diagnostic Exercises are an initiative of the Latin Comparative Pathology Group (LCPG), the Latin American subdivision of The Davis-Thompson Foundation and published in cooperation with the Brazilian Journal of Veterinary Pathology.

Editor-in-chief for this Diagnostic Exercise: Claudio Barros Associate Editor for this Diagnostic Exercise: Ingeborg Langohr.

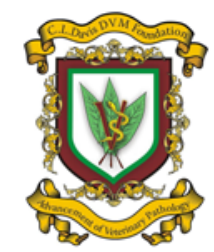


Braz J Vet Pathol, 2021, 14(1), 80 - 87

DOI: 10.24070/bjvp.1983-0246.v14i1p80-87
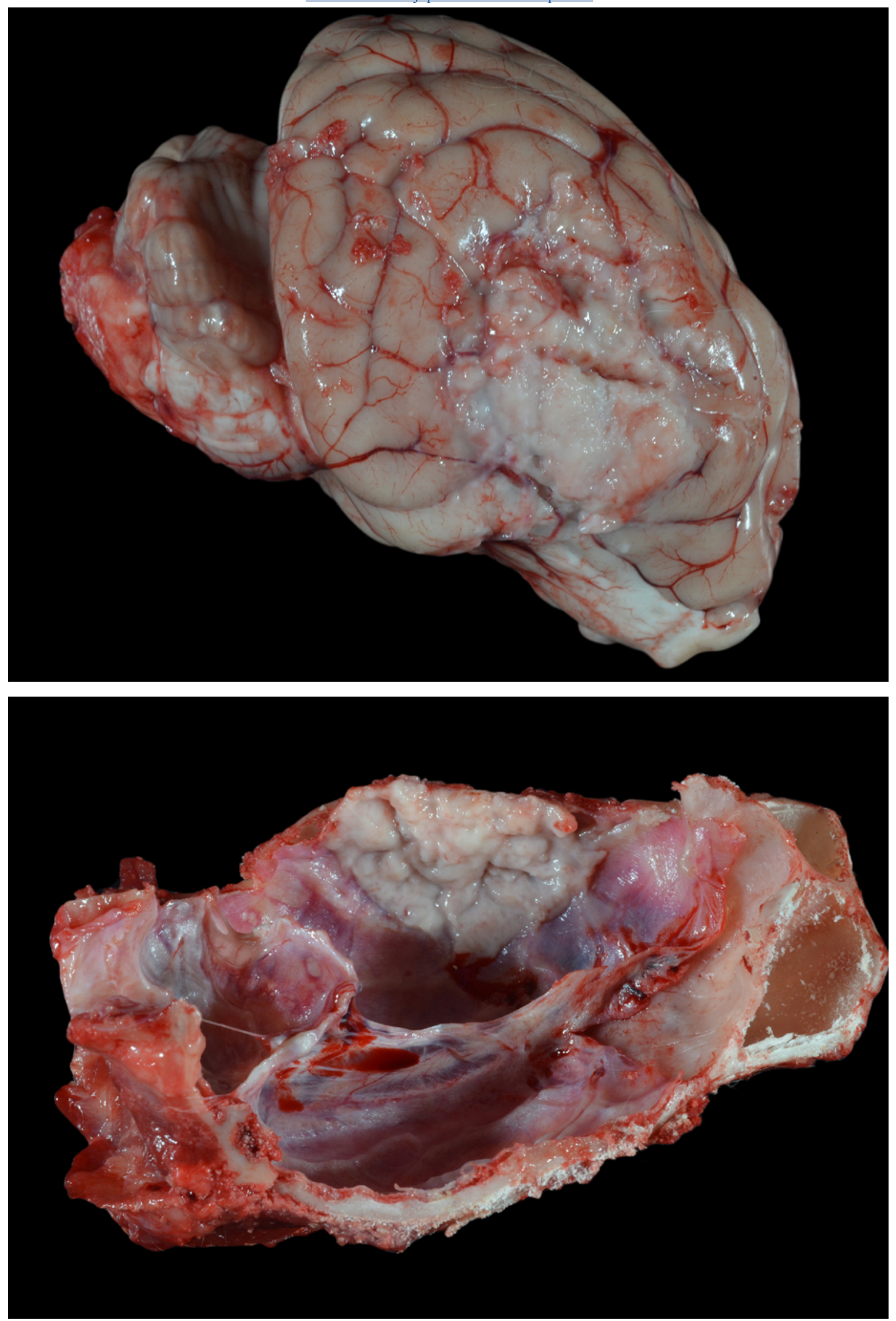

Brazilian Journal of Veterinary Pathology. www.bjvp.org.br . All rights reserved 2007-2021. 


\section{Impression smear:}

DOI: $10.24070 /$ bjvp.1983-0246.v14i1p80-87

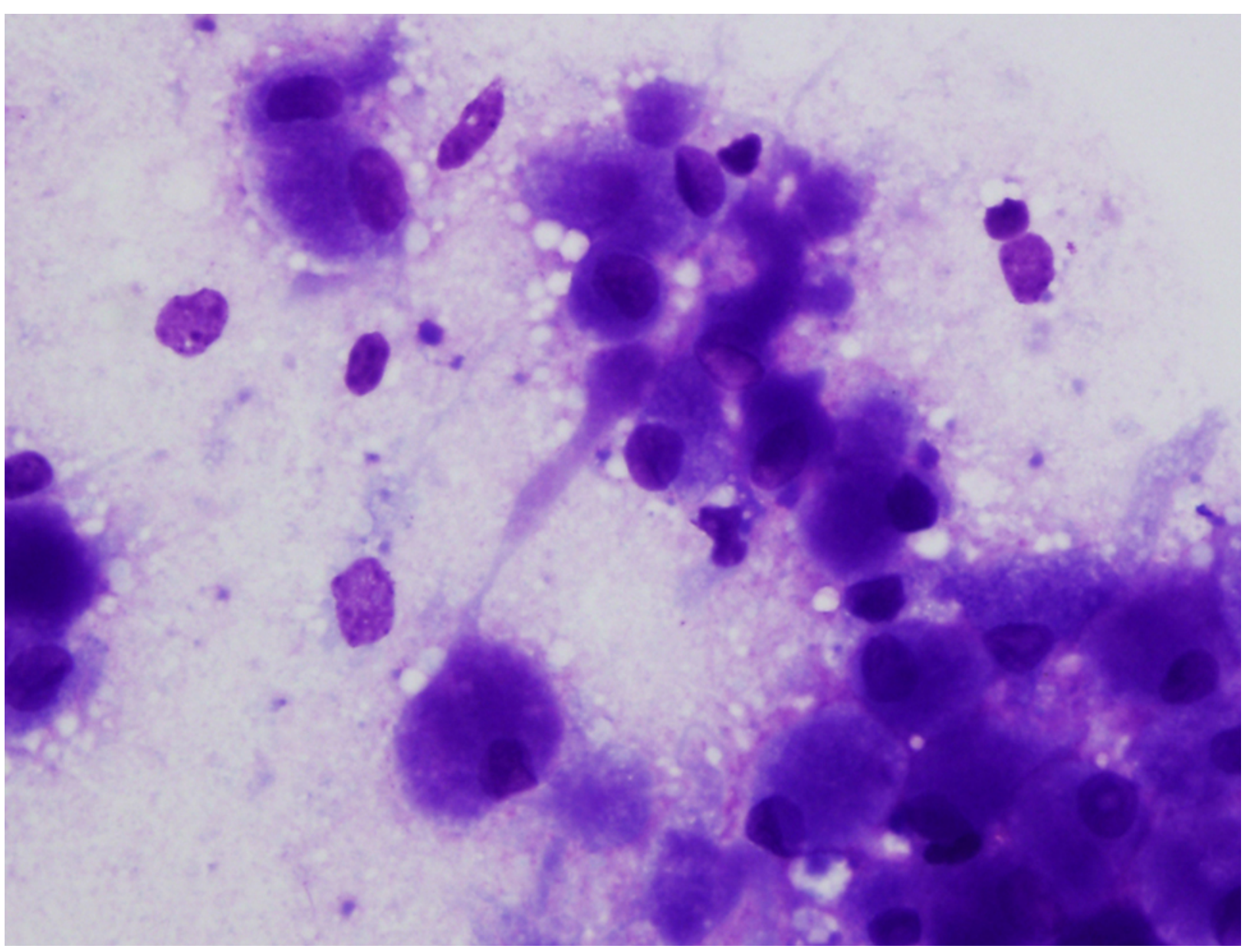

\section{Ultrastructure:}

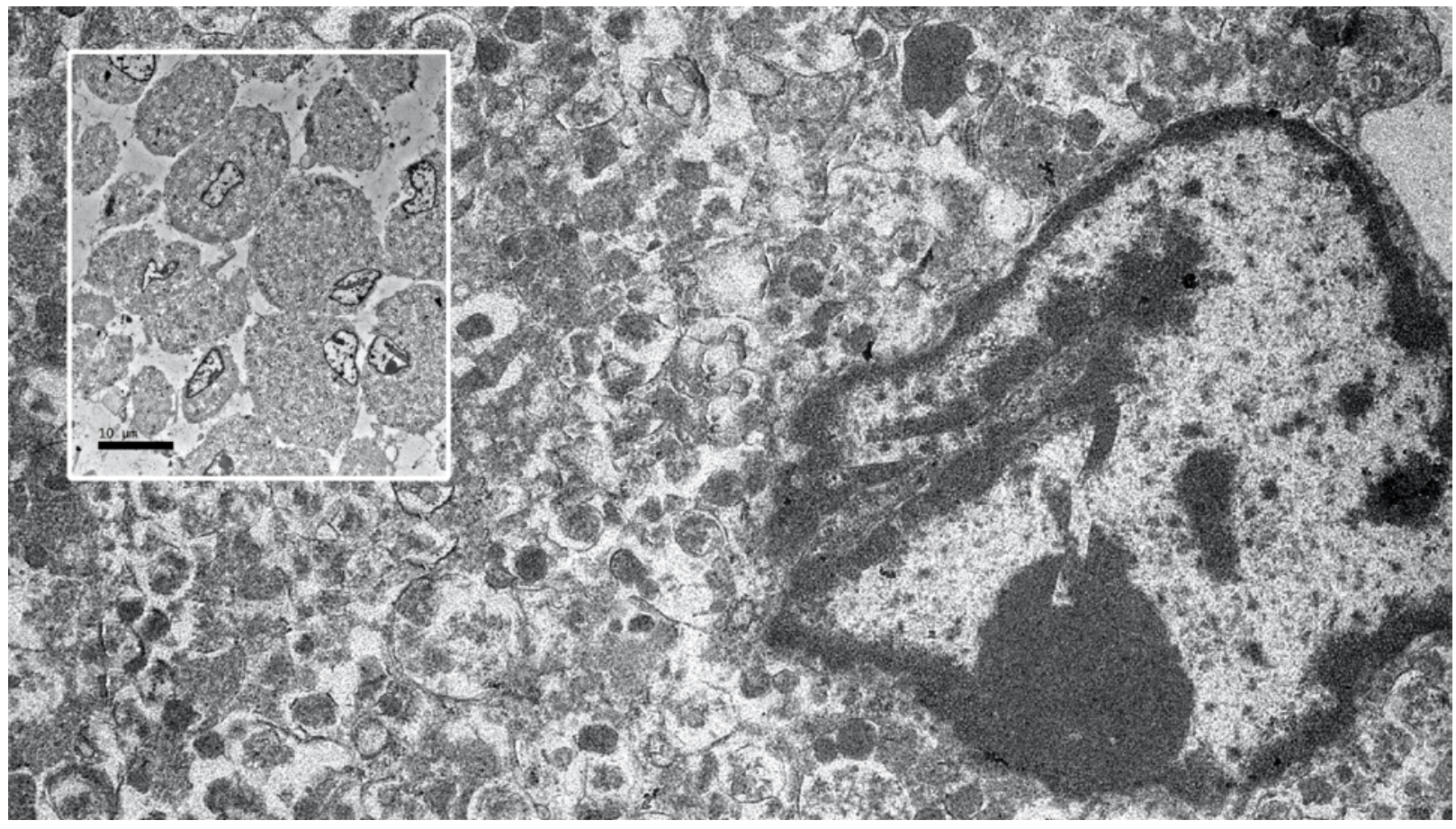


- Differential diagnoses for the gross and imaging results alone: Lymphoma, histiocytic sarcoma, meningioma, granular cell tumor

- Cytologic description of the impression smear/ cytology: In the frame examined, there are individualized round to polygonal large cells that are also arranged in cohesive clusters, and several free nuclei sit against a pale blue, finely granular to lipoid background. The cells have bland, round, eccentric nuclei with uniformly distributed chromatin, inconspicuous nucleoli, and minimal nuclear pleomorphism. There is abundant basophilic cytoplasm (nuclear:cytoplasmic ratio variably 1:3-1:5). There are no mitotic figures in the field examined.

- Ultrastructural characteristics: An inset (top left) has $\sim 10$ cells, 5 of which have an oblong to rectangular, eccentric nucleus in section. The cells are individualized (no obvious junctions at this power), round, with bland, finely granular cytoplasm. The nuclei have a thin, peripheral rim of dense chromatin. In the main figure a single cell extends to all photo borders, and a, approximately round, deeply clefted nucleus lies on the right side of the photo. Many black to dark grey lysosomes confer a granularity, which vary in their appearance, ranging from discrete dense round bodies with dense homogenous interiors to larger structures having coarse particulate contents. Other organelles are not visible in the cellular cytoplasm. The chromatin that is dense is primarily peripheralized, such that the central region of the nucleus is pale grey with sparse, scattered, and occasionally clustered fine to coarse granules.

- Cytologic description of the impression smear/ cytology: Top differential given the cytologic character: granular cell tumor.

\section{Microscopic character:}

One section of brain is examined. Replacing approximately $10 \%$ of the brain parenchyma, there is a densely cellular, poorly demarcated, unencapsulated, expansile and infiltrative mass which disrupts and extends along the meninges and invades into the surrounding parenchyma. Within the mass, there are short streams and bundles of abundant, haphazardly arranged, brightly eosinophilic fibrillar material interpreted as fibrous connective tissue of the disrupted meninges. Neoplastic cells dissect between and around meningeal fibrous connective tissue stroma. The neoplasm is composed of sheets and occasional nests of large round cells with abundant eosinophilic granular cytoplasm and distinct, sharply demarcated cell borders. Nuclei are round and eccentrically located, with finely stippled chromatin and one variably distinct nucleolus. Anisocytosis and anisokaryosis are mild, and there are no mitotic figures seen in ten 400x fields. There is rarefaction of the adjacent cerebral cortex. Nearby vascular channels have plump, prominent endothelium.

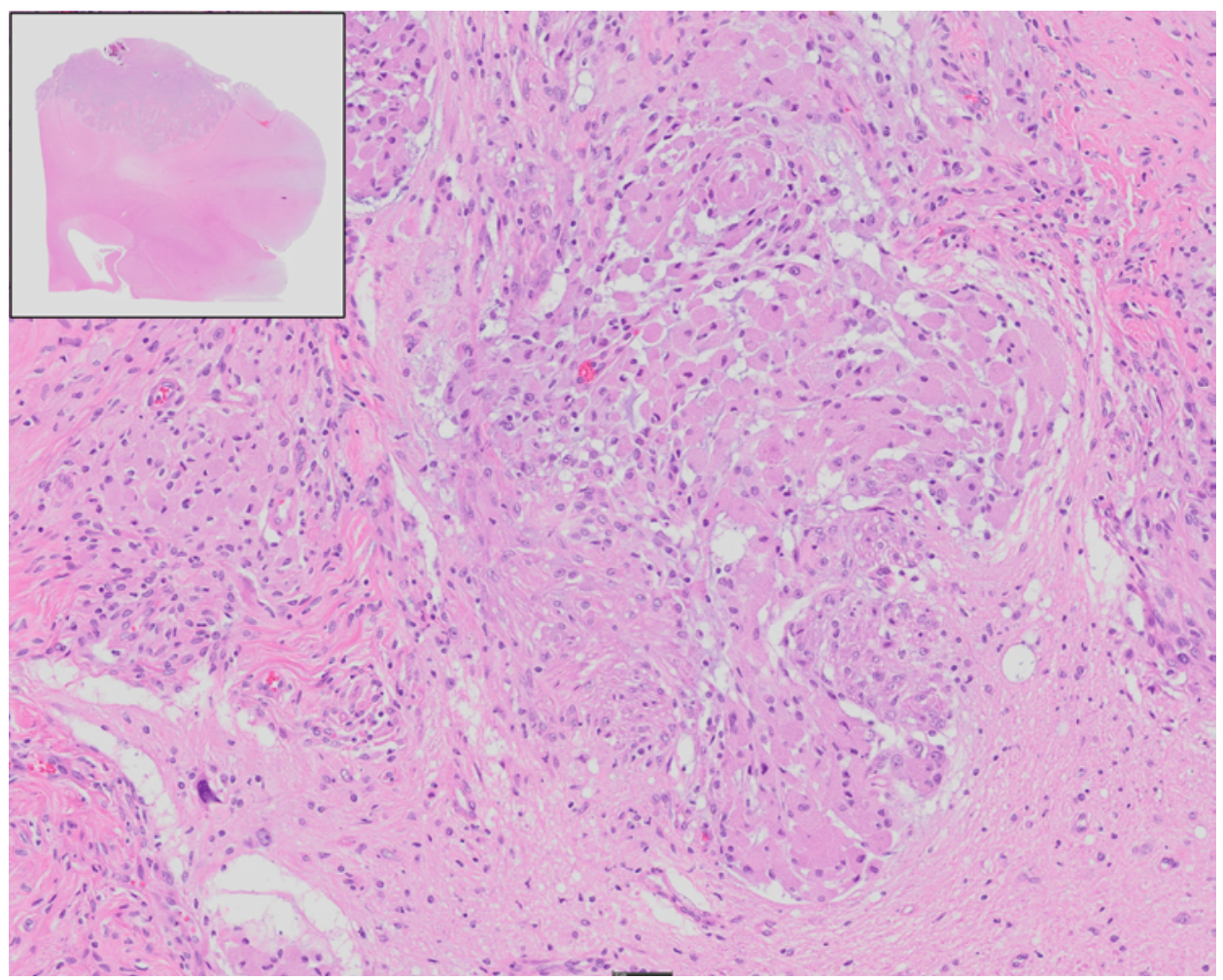

Figure 1. GCT HE with inset 
Diagnostic exercise From The Latin Comparative Pathology Group and the Davis-Thompson Foundation:

Granular Cell Tumor in the Brain of a Dog

Braz J Vet Pathol, 2021, 14(1), 80 - 87

DOI: $10.24070 /$ bjvp.1983-0246.v14ilp80-87

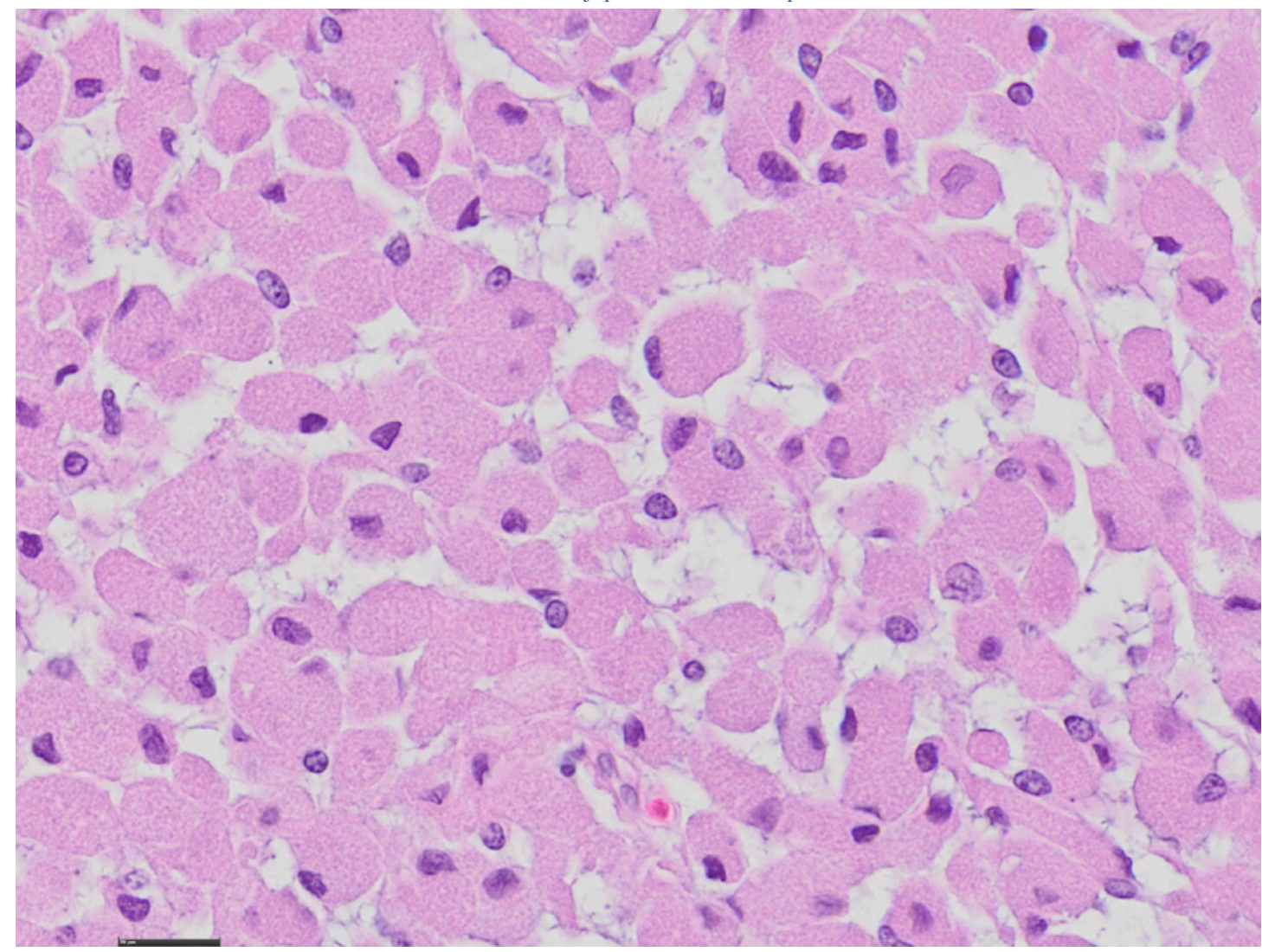

Figure 2. GCT HE high magnification

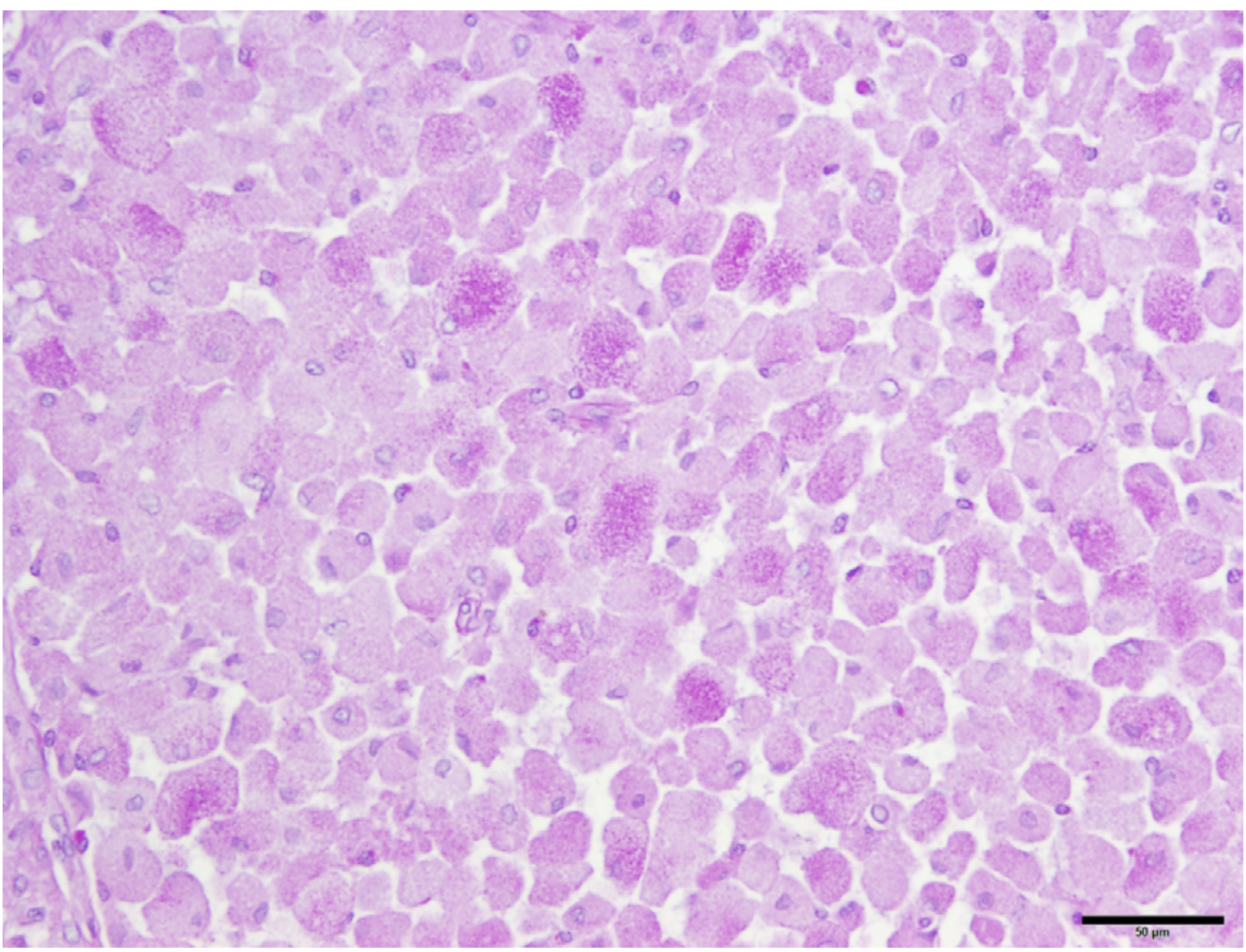

Figure 3. GCT PAS 20x

Brazilian Journal of Veterinary Pathology. www.bjvp.org.br . All rights reserved 2007-2021. 
Diagnostic exercise From The Latin Comparative Pathology Group and the Davis-Thompson Foundation: Granular Cell Tumor in the Brain of a Dog

Braz J Vet Pathol, 2021, 14(1), $80-87$

DOI: 10.24070/bjvp.1983-0246.v14i1p80-87

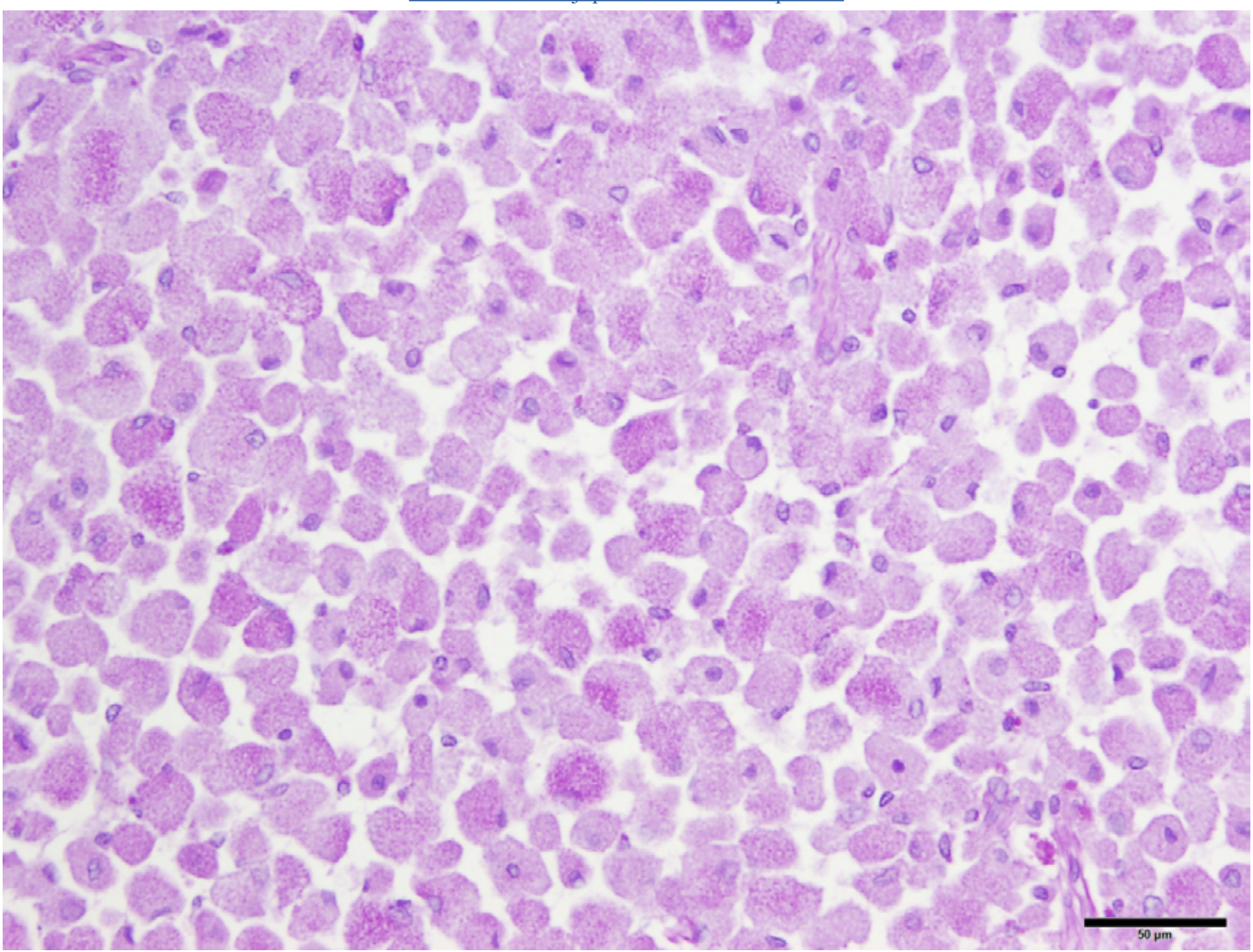

Figure 3. GCT PAS-Diastase 20x

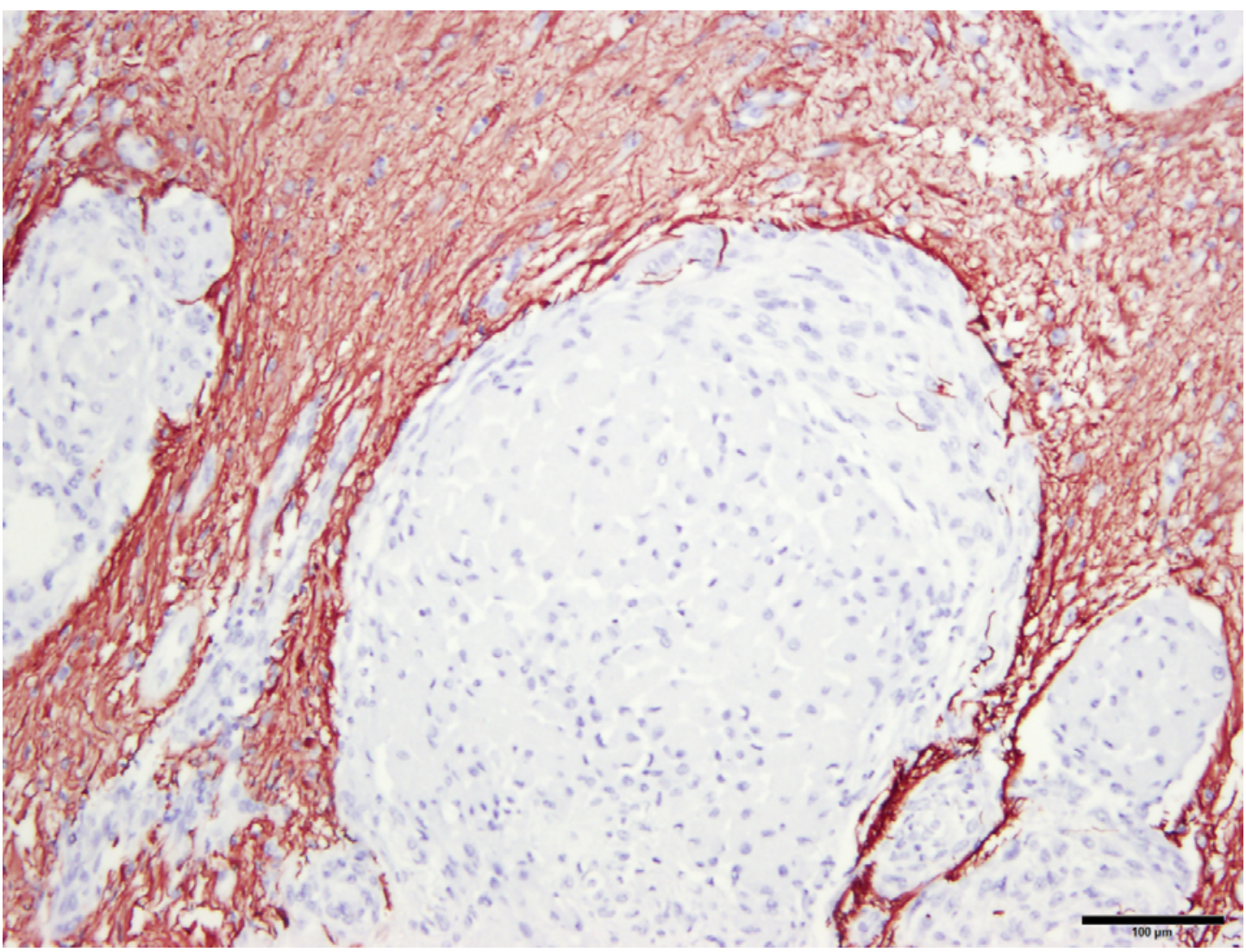

Figure 4. GCT GFAP 10x

Brazilian Journal of Veterinary Pathology. www.bjvp.org.br . All rights reserved 2007-2021. 
Braz J Vet Pathol, 2021, 14(1), $80-87$

DOI: $10.24070 /$ bjvp.1983-0246.v14ilp80-87

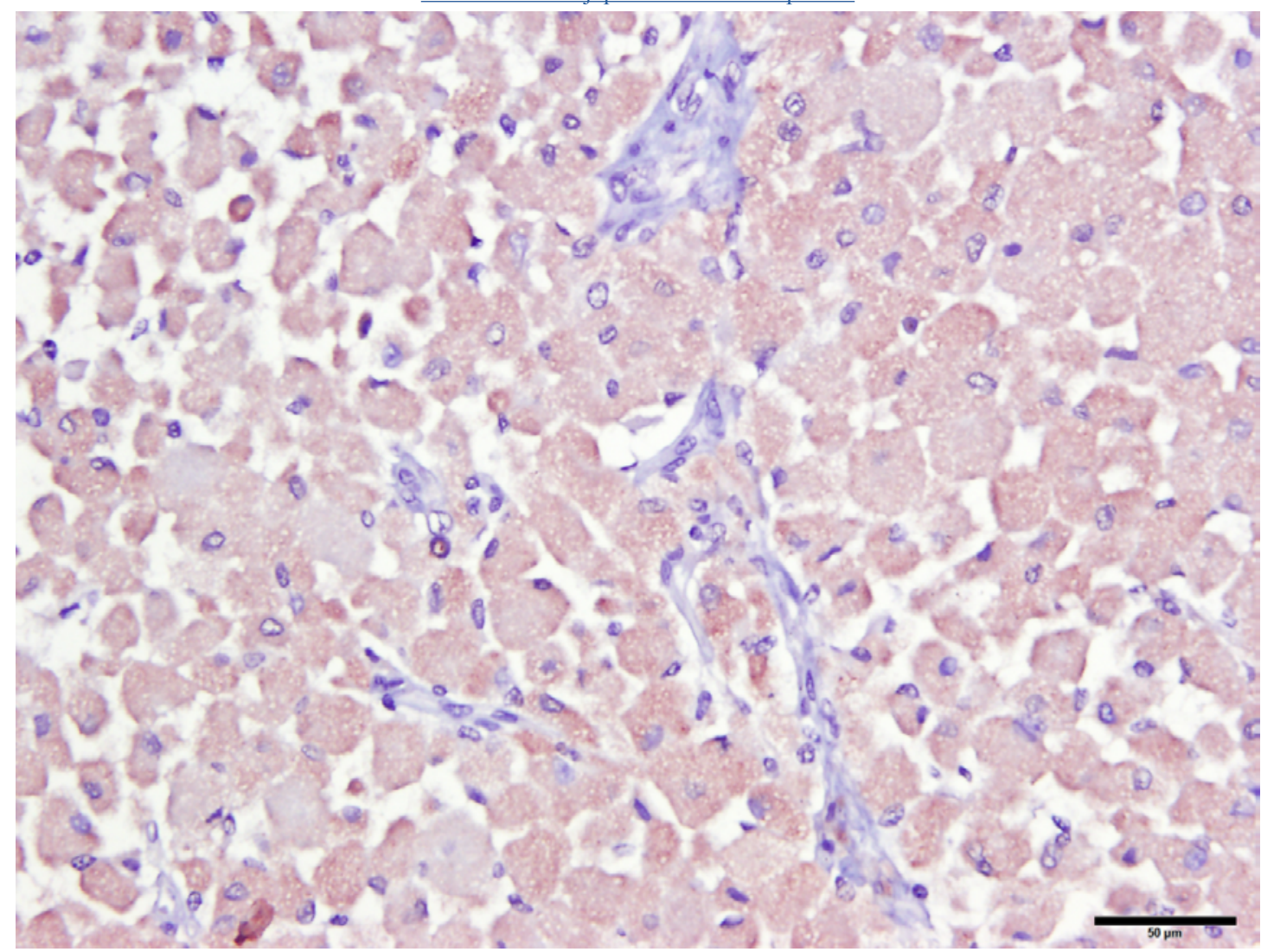

Figure 5. GCT Ubiquitin 20x

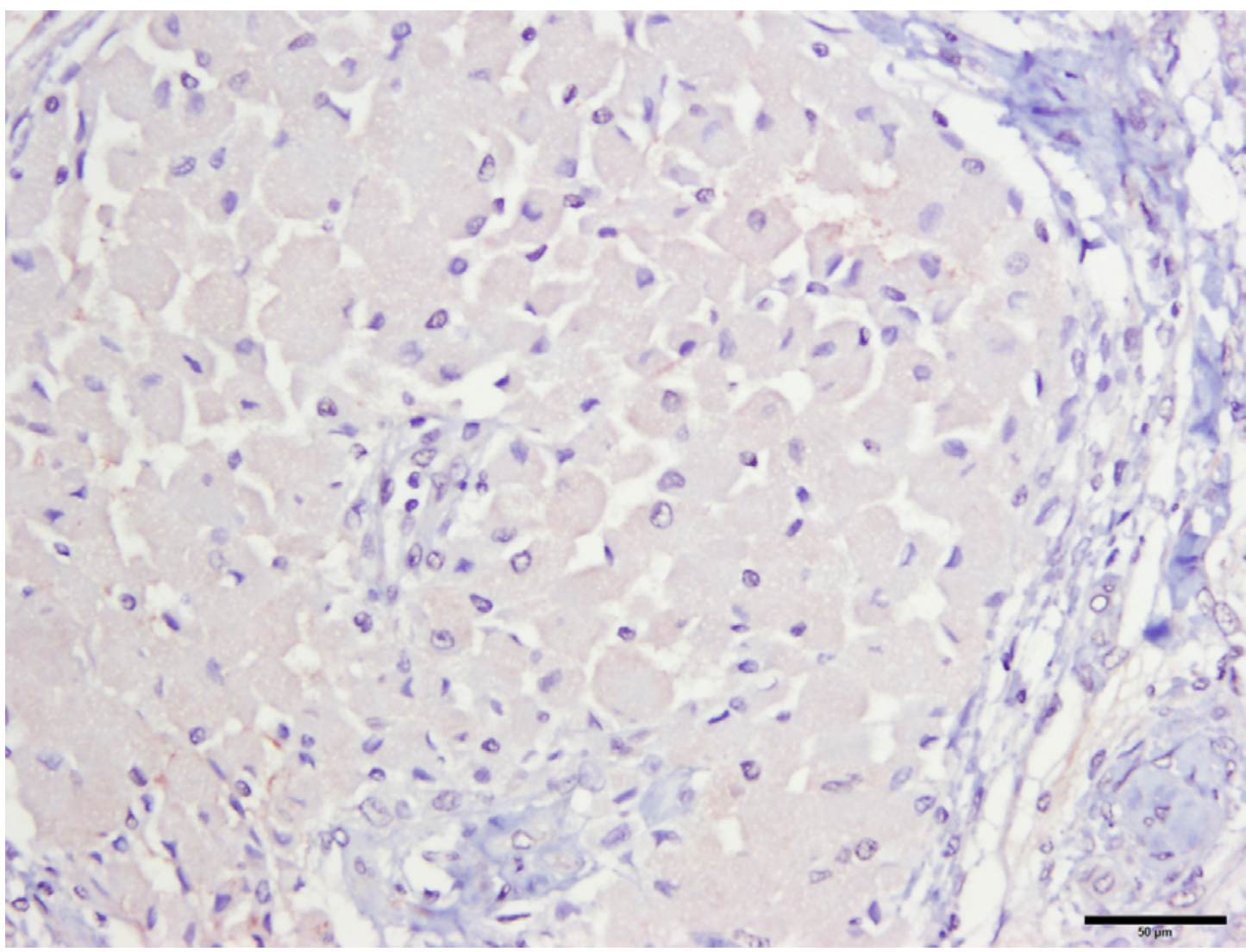

Figure 6. GCT OLIG2 20x

Brazilian Journal of Veterinary Pathology. www.bjvp.org.br . All rights reserved 2007-2021. 
Characteristic microscopy and ancillary diagnostic features:

Light microscopy: Abundant eosinophilic granular cytoplasm, eccentrically located nucleus

Special Stain and immunohistochemical stains:

- PAS/PAS plus diastase: PAS-positive granularity, resistant to diastase treatment

- Ubiquitin: reactive

- GFAP: non-reactive

- Olig2: non-reactive

\section{Morphologic diagnosis:}

Brain (Right parietal cortex and meninges): Granular Cell Tumor

\section{Discussion:}

Granular cell tumors (GCTs) are seen in a variety of species, although the cell of origin varies between species and location. In the rat, especially Sprague-Dawley, Wistar, and Fischer 344 strains, GCTs are the most common primary intracranial tumor and are often associated with the meninges. In horses, granular cell tumors are exclusively found within the airways of the lungs and are believed to form from Schwann cells. GCTs are uncommon in the dog and are typically found in the tongue or oral cavity. Case reports of canine GCTs in the brain are rare, and these tumors occur predominantly within the cerebral cortex. There are two previous case reports are described with a similar pattern of growth to this case: plaque-like growth with tight adherence to the dura mater and invasion into the cerebral cortex.

The cell of origin of the cerebral/meningeal granular cell tumor in dogs is still controversial. In humans, GCTs of the brain often occur in the neurohypophysis or infundibulum of the pituitary gland. The histogenesis of these tumors is suspected to be a specialized pituicyte. However, in the dog, intracranial GCTs are more commonly found in the meninges and the cerebral cortex, not the pituitary gland, and the cell of origin is still unknown. Intracranial GCT ultrastructural features are consistent between case reports, but immunohistochemical staining properties differ. Based on varied immunohistochemical findings, other proposed cell types of origin include oligodendrocytes, astrocytes, meningothelial cells, and Schwann cells. These varied findings suggest that granular cell tumors may have a wide variety of cell origins which are not yet well understood.
J Neuropathol Exp Neurol. 1986; 45:304-314.

2. Higgins RJ, Bollen AW, Dickinson PJ, and Siso-Llonch S. Tumors of the Nervous System. In: Meuten DJ, ed. Tumors in Domestic Animals. 5th Ed. Wiley Blackwell, Aimes, IA. 2017; 870-872.

3. Higgins RJ, LeCouteur RA, Vernau KM, et al. Granular cell tumor of the canine central nervous system: two cases. Vet Pathol. 2001; 38:620-627.

4. JPC Systemic Pathology. (March 2017). Nervous System: N-N10. Retrieved from: https://www.askjpc.org/vspo/show_page. hp?id=ZmFTTDBYZDdPVlJkRFJOMzMxU01iQT09.

5. Liu $\mathrm{CH}$, Liu CI, Liang SL, Cheng $\mathrm{CH}$, Huang SC, Lee $\mathrm{CC}$, Hsu WC, Lin YC. Intracranial granular cell tumor in a dog. J Vet Med Sci. 2004 Jan;66(1):77-9

6. Mishra S, Kent M, Haley A, Platt S, Sakamoto K. Atypical meningeal granular cell tumor in a dog. J Vet Diagn Invest. 2012 Jan;24(1):192-7

\section{References}

1. Dickson DW, Suzuki KI, Kanner R, Weitz, S, and D S Horoupian. Cerebral granular cell tumor: Immunohistochemical and electron microscopic study. 